\title{
Knowledge and Tube Feeding Practices for Older Adult Patients among Japanese Registered Nurses
}

\author{
Mihoko Ogita ${ }^{1}$, Hiroko Utsunomiya ${ }^{2}$, Kazuko Nin $^{1}$, Hidenori Arai ${ }^{{ }^{*}}$ \\ ${ }^{1}$ Department of Human Health Sciences, Kyoto University Graduate School of Medicine, Kyoto, Japan; ${ }^{2}$ Deparment of Community \\ Network and Collaborative Medicine, Kyoto University Hospital, Kyoto, Japan. \\ Email: "harai@kuhp.kyoto-u.ac.jp
}

Received January $13^{\text {th }}, 2013$; revised March $2^{\text {nd }}, 2013$; accepted April $13^{\text {th }}, 2013$

Copyright (C) 2013 Mihoko Ogita et al. This is an open access article distributed under the Creative Commons Attribution License, which permits unrestricted use, distribution, and reproduction in any medium, provided the original work is properly cited.

\begin{abstract}
The aim of this study was to examine nurses' thinking regarding the indications for tube feeding in older adults with eating difficulties and to determine whether the team approach can improve their knowledge and tube feeding practices. We sent self-administered questionnaires to 436 nurses and collected them from November to December 2010 (response rate, $70.0 \%$ ). The results indicated that approximately $30 \%$ of the Japanese nurses thought that older patients with dementia should be on tube feeding and more than half of the nurses answered that tube feeding is indicated for aspiration-prone, frail, older adults. Moreover, our findings showed that nurses who organize multidisciplinary teams performed more interventions for dysphagia before introducing tube feeding than the reference group as analyzed by multivariate adjustment (odds ratio, $2.1-6.6$ ). In conclusion, a multidisciplinary team approach is expected to make better decisions on the treatment and care of older patients with difficulty eating, including the need for tube feeding.
\end{abstract}

Keywords: Tube Feeding; Percutaneous Endoscopic Gastrostomy; Older Adults; Knowledge; Practice; Nursing; Multidisciplinary Team

\section{Introduction}

Tube feeding decisions in elderly patients with various advanced comorbidities are challenging decisions with complicated issues. Many older patients have nutritional problems caused by eating difficulties due to stroke, cancer, dementia, and others causes. In cases in which patients have a functional gastrointestinal tract but cannot take in sufficient nutrition orally, tube feeding with a nasogastric tube (NGT), percutaneous endoscopic gastrostomy (PEG) or enterostomy is an option. In Japan, no guidelines have been published yet for tube feeding, including PEG, in the elderly, especially in demented patients. Physicians often need to make decisions in those cases with uncertain prognosis, and this decision-making process is poorly understood. This may be one of the reasons for explaining the higher percentage of tube feeding in demented patients in Japan than in western countries; approximately $5 \%-30 \%$ of the advanced demented patients in a nursing home are on tube feeding in Europe and the United States, while in Japan about $50 \%$ of those patients are on tube feeding [1-4].

"Corresponding author.
In addition, the quality of life (QOL) in the elderly with tube feeding, including PEG, and its effects on longterm survival have not been fully determined [5-11]. A recent study showed that more than half of geriatric patients with PEG may survive longer than 2 years [12], which is longer than in Europe and the United States. However, this finding may be explained by the fact that the introduction of PEG in Japan is carried out at an earlier stage of dementia or other comorbidities.

According to our previous study, over $90 \%$ of geriatricians answered that "neurological disorder" and "stroke" are indications for tube feeding, including PEG, whereas approximately $50 \%$ of them answered that "dementia" is an indication for tube feeding [13]. Moreover, geriatricians who organized a multidisciplinary team tended to perform more interventions and care for dysphagia compared with the group that had "no or a few multidisciplinary teams" [13]. Thus, it is important to clarify the thoughts of nurses for tube feeding as healthcare providers and team members of a multidisciplinary team, because nurses have a different role and educational background. It would be intriguing if we can find different thoughts for tube feeding between geriatricians and nurses. 
Therefore, this study aimed to examine nurses' thinking regarding the indications for tube feeding in elderly patients with eating difficulties and several disorders and to determine whether the team approach can affect their knowledge and tube feeding practices. Our results could be utilized to improve tube feeding care among Japanese older adult patients.

\section{Methods}

This study was a cross-sectional study that recruited all nurses who worked at Kyoto University Hospital as a registered nurse into the study. The exclusion criteria were those nurses who had not dealt with patients requiring tube feeding over the last two years and nurse managers. We sent self-administered questionnaires to a total of 436 nurses from all departments and then separately collected the responses from November to December 2010. This study was approved by the Ethics Committee of Kyoto University Graduate School and Faculty of Medicine (No. E984, 2010).

The questionnaires included demographic information, such as age, sex, clinical experience, workplace experiences and tube feeding experience, knowledge and tube feeding practices (aims and indications for tube feeding), interventions for dysphagia before using tube feeding, information for tube feeding and the multidisciplinary team approach to verify the necessity of tube feeding indication. The term "elderly" was defined in the questionnaire as people over the age of 75 years and those who require nursing care, and "tube feeding" was defined as all types of tube feeding nutrition including NGT, PEG and enterostomy tube.

We performed descriptive analyses for each item in the questionnaire. Chi-square tests and t-tests were used to compare the differences in clinical experiences, experiences in the workplace and experiences with tube feeding care. The number of clinical experiences was divided according to the median into two groups. The experiences in the workplace were also divided into two groups: 1) persons who work only in the hospital and 2) persons who work in a clinic, long-term care facility or home-visit nursing facility. The experiences of tube feeding care were divided into three groups. Nurses who experienced more than one case of tube feeding care were divided into two groups by median. Logistic regression analyses were performed to evaluate the differences in team members and their frequencies on the team according to the indication for tube feeding; the interventions for dysphagia; and the information for tube feeding. Each item was adjusted for sex, clinical experience, experiences in the workplace and experience with tube feeding care. The frequency and number of members in a multidisciplinary team were divided into five categories: 1) not at all; 2) occasionally with less than four different health care professionals; 3 ) occasionally with four different health care professionals; 4) every time with less than four different health care professionals; and 5) every time with four different health care professionals. The Statistical Package for Social Sciences, version 18.0J (SPSS Japan Inc., Tokyo, Japan) was used for statistical analysis. All probability values were two-tailed with a significance level of $\mathrm{p}<0.05$, and all confidence intervals were estimated at the $95 \%$ level.

\section{Results}

A total of 305 of the 436 recruited nurses responded to the questionnaire, yielding a response rate of $70.0 \%$. After excluding the questionnaires with missing data, we analyzed the remaining 286 questionnaires. The age distribution of nurses in this study was the following: $59.1 \%$ were in their $20 \mathrm{~s}, 30.4 \%$ were in their $30 \mathrm{~s}, 7.7 \%$ were in their $40 \mathrm{~s}, 2.4 \%$ were in their $50 \mathrm{~s}$, and $0.3 \%$ were in their $60 \mathrm{~s}$. Female nurses represented $92.7 \%$ of the total. In terms of the education levels, $42.7 \%$ had a bachelor degree, and the others graduated from nursing college. We found that $56.3 \%$ of the nurses had more than 5 years of clinical experience, $92.0 \%$ only had experiences working in hospitals and $8.0 \%$ had work experiences in other facilities, such as long-term care facilities or home-visit nursing stations.

Table 1 shows the percentage of nurses and their responses for the purpose and indications for tube feeding, grouped by nurses' clinical experiences and tube feeding experiences. Forty-two percent of the nurses chose "improvement of quality of life" and $37.1 \%$ chose "improvement of general condition or prevention of complications" as the purpose for tube feeding. In contrast, few nurses chose "satisfaction of the patient" and none chose "living will". We did not find any effect of personal characteristics on nurses' reasons for the tube feeding. Among the seven target indications for tube feeding in the elderly, more than $80 \%$ of the nurses answered that "neurological disorders", "oropharyngeal malignancy", "head injury or facial trauma" and "stroke" were indications for tube feeding. In contrast, $26.9 \%$ of the nurses answered that "dementia" was an indication for tube feeding, and 53.1\% answered that "aspirationprone, frail, and elderly without comorbidities" was an indication. The percentage of nurses who answered that "aspiration-prone, frail, and elderly without comorbidities" was an indication was significantly higher in those nurses with more than 5 years of clinical experience than in those nurses with less than 5 years of clinical experience" $(64.6 \%$ vs $38.4 \%, \mathrm{p}<$ $0.001)$. Additionally, the percentage of nurses who answered that "aspiration-prone, frail, and elderly without comorbidities" was an indication was significantly higher in those nurses with work experiences in other hospitals than in those without such experiences $(87.0 \%$ vs $50.2 \%$, 
Table1. Knowledge about aims of tube feeding and indications for tube feeding according to characteristics of nurses.

\begin{tabular}{|c|c|c|c|c|c|c|c|c|c|c|c|}
\hline \multirow[b]{3}{*}{ Questions } & \multicolumn{10}{|c|}{ Characteristics of nurses } & \multirow{3}{*}{$\begin{array}{c}\text { Total } \\
n=286\end{array}$} \\
\hline & \multicolumn{3}{|c|}{ Clinical experience } & \multicolumn{3}{|c|}{ Histroy of working place } & \multicolumn{4}{|c|}{ Experience of tube feeding care } & \\
\hline & $\begin{array}{l}<5 \text { years } \\
\mathrm{n}=125\end{array}$ & $\begin{array}{l}\geqq 5 \text { years } \\
\mathrm{n}=161\end{array}$ & $\mathrm{p}$ value & $\begin{array}{c}\text { Only } \\
\text { hospital } \\
n=263\end{array}$ & $\begin{array}{l}\text { Other }^{* 1} \\
\mathrm{n}=23\end{array}$ & $\mathrm{p}$ value & $\begin{array}{c}\text { non } \\
\mathrm{n}=52\end{array}$ & $\begin{array}{c}1-5 \text { cases } \\
n=105\end{array}$ & $\begin{array}{l}\geqq 6 \text { cases } \\
\mathrm{n}=129\end{array}$ & $\mathrm{p}$ value & \\
\hline \multicolumn{12}{|l|}{$\begin{array}{c}\text { What are the aims of TF in } \\
\text { your patient care?' }\end{array}$} \\
\hline Improvement of survival & $26(20.8)$ & $16(9.9)$ & N.D & $35(13.3)$ & $7(30.4)$ & N.D & $14(26.9)$ & $14(13.3)$ & $14(10.9)$ & N.D & $42(14.7)$ \\
\hline $\begin{array}{l}\text { Improvement of general } \\
\text { condition and prevention of } \\
\text { complications }\end{array}$ & $44(35.2)$ & $62(38.5)$ & & $101(38.4)$ & $5(21.7)$ & & $15(28.8)$ & $48(45.7)$ & $43(33.3)$ & & $106(37.1)$ \\
\hline $\begin{array}{l}\text { Improvement of activities of } \\
\text { daily living }\end{array}$ & $3(2.4)$ & $5(3.1)$ & & $7(2.7)$ & $1(4.3)$ & & $1(1.9)$ & $3(2.9)$ & $4(3.1)$ & & $8(2.8)$ \\
\hline $\begin{array}{l}\text { Improvement of } \\
\text { quality of life }\end{array}$ & $48(38.4)$ & $72(44.7)$ & & $112(42.6)$ & $8(34.8)$ & & $21(40.4)$ & $38(36.2)$ & $61(47.3)$ & & $120(42.0)$ \\
\hline Satisfaction of patient & $4(3.2)$ & $4(2.5)$ & & $7(2.7)$ & $1(4.3)$ & & $1(1.9)$ & $2(1.9)$ & $5(3.9)$ & & $8(2.8)$ \\
\hline Burden of caregiver & $0(0.0)$ & $1(0.6)$ & & $0(0.0)$ & $1(4.3)$ & & $0(0.0)$ & $0(0.0)$ & $1(0.8)$ & & $1(0.3)$ \\
\hline Length of hospital stay & $0(0.0)$ & $0(0.0)$ & & $0(0.0)$ & $0(0.0)$ & & $0(0.0)$ & $0(0.0)$ & $0(0.0)$ & & $0(0.0)$ \\
\hline Living will & $0(0.0)$ & $0(0.0)$ & & $0(0.0)$ & $0(0.0)$ & & $0(0.0)$ & $0(0.0)$ & $0(0.0)$ & & $0(0.0)$ \\
\hline Other & $00(0.0)$ & $1(0.6)$ & & $1(0.4)$ & $0(0.0)$ & & $0(0.0)$ & $0(0.0)$ & $1(0.8)$ & & $1(0.3)$ \\
\hline \multicolumn{12}{|l|}{$\begin{array}{l}\text { Is the following disorder an } \\
\text { indication for TF? }\end{array}$} \\
\hline Head injury or facial trauma & $109(87.2)$ & $150(93.2)$ & 0.087 & $237(90.1)$ & $22(95.7)$ & $0.708^{\pi}$ & $44(84.6)$ & $94(89.5)$ & $121(93.8)$ & $0.145^{\pi}$ & $259(90.6)$ \\
\hline Oropharyngeal malignancy & $114(91.2)$ & $150(93.2)$ & 0.536 & $241(91.6)$ & $23(100.0)$ & $0.234^{\pi}$ & $45(86.5)$ & $97(92.4)$ & $122(94.6)$ & $0.190^{\pi}$ & $264(92.3)$ \\
\hline Neurological disorder & $111(88.8)$ & $153(95.0)$ & 0.050 & $241(91.6)$ & $23(100.0)$ & $0.234^{\pi}$ & $43(82.7)$ & $97(92.4)$ & $124(96.1)$ & $0.012^{\pi}$ & $264(92.3)$ \\
\hline Stroke & $103(82.4)$ & $142(88.2)$ & 0.165 & $222(84.4)$ & $23(100.0)$ & $0.055^{\pi}$ & $40(76.9)$ & $93(88.6)$ & $112(86.8)$ & 0.129 & $245(85.7)$ \\
\hline Dementia & $29(23.2)$ & $48(29.8)$ & 0.211 & $71(27.0)$ & $6(26.1)$ & 0.925 & $8(15.4)$ & $24(22.9)$ & $45(34.9)$ & 0.014 & $77(26.9)$ \\
\hline $\begin{array}{l}\text { Aspiration-prone frail } \\
\text { elderly without comorbidity }\end{array}$ & $48(38.4)$ & $104(64.6)$ & $<0.001$ & $132(50.2)$ & $20(87.0)$ & 0.001 & $19(36.5)$ & $52(49.5)$ & $81(62.8)$ & 0.004 & $152(53.1)$ \\
\hline $\begin{array}{l}\text { Malnutrition in frail elderly } \\
\text { without comorbidity }\end{array}$ & $23(18.4)$ & $44(27.3)$ & 0.077 & $58(22.1)$ & $9(39.1)$ & 0.064 & $5(9.6)$ & $18(17.1)$ & $44(34.1)$ & $<0.001$ & $67(23.4)$ \\
\hline \multicolumn{12}{|l|}{$\begin{array}{l}\text { How long does a patient } \\
\text { need to survive after PEG } \\
\text { placement? }\end{array}$} \\
\hline 2 weeks & $5(4.0)$ & $3(1.9)$ & $0.049^{\natural}$ & $8(3.0)$ & $0(0.0)$ & $0.467^{\curvearrowleft}$ & $4(7.7)$ & $4(3.8)$ & $0(0.0)$ & $0.020^{\pi}$ & $8(2.8)$ \\
\hline 4 weeks & $19(15.2)$ & $11(6.8)$ & & $28(10.6)$ & $2(8.7)$ & & $8(15.4)$ & $15(14.3)$ & $7(5.4)$ & & $30(10.5)$ \\
\hline 6 weeks & $12(9.6)$ & $9(5.6)$ & & $20(7.6)$ & $1(4.3)$ & & $4(7.7)$ & $7(6.7)$ & $10(7.8)$ & & $21(7.3)$ \\
\hline 8 weeks & $19(15.2)$ & $26(16.1)$ & & $44(16.7)$ & $1(4.3)$ & & $7(13.5)$ & $14(13.3)$ & $24(18.6)$ & & 45 (15.7) \\
\hline 12 weeks & $70(56.0)$ & $112(69.6)$ & & $163(62.0)$ & $19(82.6)$ & & $29(55.8)$ & 65 (61.9) & $88(68.2)$ & & $182(63.6)$ \\
\hline $\begin{array}{l}\text { How long does a patient } \\
\text { need to survive after PEG } \\
\text { placement? } \geqq 12 \text { weeks }\end{array}$ & $70(56.0)$ & $112(69.6)$ & 0.018 & $163(62.0)$ & $19(82.6)$ & 0.049 & $29(55.8)$ & 65 (61.9) & $88(68.2)$ & 0.260 & $182(63.6)$ \\
\hline
\end{tabular}

Number (\%), p values were tested by Chi-square test, "p values were tested by Fisher's exact test. ${ }^{\dagger}$ Simple answer was allowed, other questioners were multiple answers. ${ }^{\ddagger}$ Limited life after PEG placement was divided into 2 groups, which was used median. ${ }^{* 1}$ Other was included clinic, long-term care facility and home-visit nursing station. TF: Tube Feeding; PEG: Percutaneous Endoscopic Gastrostomy; N.D: Not Dedetermined. 
$\mathrm{p}=0.001)$; moreover, the percentage was higher in those with more tube feeding experience than in those with none or less experience $(p=0.004)$. The percentage of positive responses for "neurological", "dementia" and "malnutrition in frail elderly without comorbidities" as tube feeding indications was also significantly higher in those nurses with more tube feeding experience than in those with none or less experience (neurological disorder: $\mathrm{p}=0.012$, dementia: $\mathrm{p}=0.014$, aspiration-prone frail elderly without comorbidities: $\mathrm{p}<0.001)$. We also asked about the life expectancy of patients after PEG placement, and $63.6 \%$ answered that at least more than 12 weeks was necessary.

Table 2 shows the nursing care practices before starting tube feeding according to the characteristics of the nurses. We asked how many interventions they performed for patients with swallowing disorders before patients began tube feeding. The mean number of interventions was 6.38 items, and as expected, nurses with more than 5 years of experience performed significantly more interventions than those with less than 5 years $(6.84 \pm 3.0$ vs $5.49 \pm 2.8$, respectively, $\mathrm{p}=0.001$ ), and nurses with longer experiences with tube feeding performed significantly more interventions than those with shorter experiences $(7.05 \pm 3.1$ vs $5.54 \pm 2.8, \mathrm{p}<0.001)$. The number of interventions was not significantly affected by workplace experiences. Among 15 intervention items for a swallowing disorder, more than $70 \%$ of nurses answered that "thickening agent" and "using semi-solid and liquid foods" were used in patients with a swallowing disorder. The percentage of nurses who performed "video endoscopy", "video fluorography", "oral ice-massage", "vocalization exercise", "positioning", "appropriate approach for swallowing" and "ways to cope when aspirating" were higher in nurses with more tube feeding experience. In relation to the amount of information about tube feeding the nurses gave to patients before using tube feeding, the mean number of information items was 6.61 items, and nurses with more than 5 years of experiences, history of working in other places or more tube feeding experience gave significantly more information such as "better nutritional condition compared to IVH", "technique for the management of tube feeding", and "caregiver burden" than other groups.

In terms of organizing a multidisciplinary team for tube feeding, $72 \%$ of nurses discussed tube feeding with other health care professionals every time or occasionally. The mean number of team members was 3.42 and among the members there were physicians $(98.2 \%)$, primary nurses $(82.7 \%)$, speech therapists $(59.5 \%)$ and discharge planning coordinators $(31.0 \%)$ (Table 3$)$.

Table 4 shows the multiple logistic regression analyses for the team members and their frequencies on the team according to the knowledge and tube feeding prac- tices. More "interventions for dysphagia before introducing tube feeding" were performed by nurses who organized a multidisciplinary team than the reference group, as determined by multivariate adjustment (odds ratio: occasional and less than four different health care professionals, 2.1; occasional and four different health care professionals, 4.7; every time and less than four different health care professionals, 1.8 ; every time and four different health care professionals, 6.6). We also found that nurses who always organize a team with several healthcare specialties (multidisciplinary) performed more tests for the assessment of swallowing function and interventions for dysphagia, such as oral ice massage. Additionally, theses nurses provided more information on tube feeding (odd ratio: 4.7) than the reference group. However, the indications for tube feeding were not affected by multidisciplinary team results. Education levels were well correlated with clinical experiences, therefore they were not adjusted in multivariate analysis.

\section{Discussion}

In this study, we found that the majority of nurses thought the purpose of tube feeding was the improvement of QOL in the elderly with eating problems. The decision making by nurses on tube feeding, including PEG, does not seem to be related to their clinical experiences or experiences in their workplace. We previously showed that "improvement of general condition and prevention of complications" was a relevant priority for initiating tube feeding by Japanese geriatricians [13]. Therefore, the reason for initiating tube feeding in older patients is different between doctors and nurses. In elderly cases with end-of-life decision-making, nurses seem to make a decision based on the patient's wishes more than doctors [14]. Although the definition of QOL might differ between nurses and doctors, the conception of care to nurses may be more comprehensive than to physicians.

Several studies have indicated that there is no survival benefit in demented patients who receive artificial tube feeding $[5,6,8,10]$. In addition, "Guidelines for parenteral and enteral nutrition in the elderly in Europe" does not recommend tube feeding to persons with severe dementia due to the prevalent risks compared with the benefits. However, they occasionally recommend tube feeding in cases of early and moderate dementia to ensure energy and nutrient supply and to prevent undernutrition $[15,16]$. In the present study, we found that approximately $26 \%$ of the nurses considered that demented patients with loss of appetite or eating apraxia should be on tube feeding. Although the Japanese guidelines for tube feeding in the elderly are expected to be available in the near future, nurses were still carefully thinking about the indication for tube feeding in patients with dementia. We also found that $53 \%$ of the nurses thought that aspiration-prone, frail, 
Table2. Practice of nursing care before introducing tube feeding according to characteristics of nurses.

\begin{tabular}{|c|c|c|c|c|c|c|c|c|c|c|}
\hline \multirow[b]{3}{*}{ Questions } & \multicolumn{9}{|c|}{ Characteristics of nurses } & \multirow{3}{*}{$\begin{array}{c}\text { Total } \\
\mathrm{n}=234\end{array}$} \\
\hline & \multicolumn{3}{|c|}{ Clinical experience } & \multicolumn{3}{|c|}{ Histroy of working place } & \multicolumn{3}{|c|}{ Experience of tube feeding care } & \\
\hline & $\begin{array}{l}<5 \text { years } \\
\mathrm{n}=80\end{array}$ & $\begin{array}{l}\geqq 5 \text { years } \\
\mathrm{n}=154\end{array}$ & $\mathrm{p}$ value & $\begin{array}{c}\text { Only } \\
\text { hospital } \\
\mathrm{n}=212\end{array}$ & $\begin{array}{l}\text { Other }^{* 1} \\
\mathrm{n}=22\end{array}$ & $\mathrm{p}$ value & $\begin{array}{c}1-5 \text { cases } \\
\mathrm{n}=105\end{array}$ & $\begin{array}{l}\geqq 6 \text { cases } \\
\mathrm{n}=129\end{array}$ & $\mathrm{p}$ value & \\
\hline \multicolumn{11}{|l|}{$\begin{array}{l}\text { Interventions for } \\
\text { swallowing disorder }\end{array}$} \\
\hline $\begin{array}{c}\text { No. Interventions; } \\
\text { mean }+/- \text { standard deviation } \\
\text { (total } 15 \text { items) }\end{array}$ & $5.49 \pm 2.82$ & $6.84 \pm 3.03$ & $0.001^{\S}$ & $6.29 \pm 3.05$ & $7.23 \pm 2.65$ & $0.131^{*}$ & $5.54 \pm 2.76$ & $7.05 \pm 3.07$ & $<0.001^{\S}$ & $6.38 \pm 3.02$ \\
\hline $\begin{array}{l}\text { No. Interventions, } \geqq 6 \text { items }{ }^{\dagger} \\
\quad \text { (total } 15 \text { items) }\end{array}$ & $38(47.5)$ & $95(61.7)$ & 0.038 & $116(54.7)$ & $17(77.3)$ & 0.042 & $47(44.8)$ & $86(66.7)$ & 0.001 & $133(56.8)$ \\
\hline \multicolumn{11}{|l|}{ [Consultation] } \\
\hline To otolaryngologist & $18(22.5)$ & $67(43.5)$ & 0.002 & $77(36.3)$ & $8(36.4)$ & 0.997 & $32(30.5)$ & $53(41.1)$ & 0.093 & $85(36.3)$ \\
\hline To speech therapist & $53(66.3)$ & $102(66.2)$ & 0.998 & $144(67.9)$ & $11(50.0)$ & 0.091 & $64(61.0)$ & $91(70.5)$ & 0.123 & $155(66.2)$ \\
\hline $\begin{array}{l}\text { To certified nurse of } \\
\text { dysphagia nursing }\end{array}$ & $15(18.8)$ & $46(29.9)$ & 0.066 & $54(25.5)$ & $7(31.8)$ & 0.519 & $23(21.9)$ & $38(29.5)$ & 0.191 & $61(26.1)$ \\
\hline \multicolumn{11}{|l|}{ [Test] } \\
\hline $\begin{array}{l}\text { Repetitive saliva } \\
\text { swallowing test }\end{array}$ & $5(6.3)$ & $23(14.9)$ & 0.052 & $23(10.8)$ & $5(22.7)$ & $0.156^{\oplus}$ & $10(9.5)$ & $18(14.0)$ & 0.299 & $28(12.0)$ \\
\hline Water swallowing test & $32(40.0)$ & $71(46.1)$ & 0.372 & $89(42.0)$ & $14(63.6)$ & 0.051 & $43(41.0)$ & $60(46.5)$ & 0.394 & $103(44.0)$ \\
\hline Video endoscopy & $2(2.5)$ & $12(7.8)$ & $0.147^{\bullet}$ & $13(6.1)$ & $1(4.5)$ & $1.000^{\top}$ & $2(1.9)$ & $12(9.3)$ & 0.018 & $14(6.0)$ \\
\hline Video fluorography & $5(6.3)$ & $21(13.6)$ & 0.088 & $24(11.3)$ & $2(9.1)$ & $1.000^{\bullet}$ & $5(4.8)$ & $21(16.3)$ & 0.005 & $26(11.1)$ \\
\hline \multicolumn{11}{|l|}{ [Practice and education] } \\
\hline Oral ice-massage & $32(40.0)$ & $90(58.4)$ & 0.007 & $110(51.9)$ & $12(54.5)$ & 0.812 & $45(42.9)$ & $77(59.7)$ & 0.010 & $122(52.1)$ \\
\hline Swallowing exercise & $30(37.5)$ & $65(42.2)$ & 0.487 & $84(39.6)$ & $11(50.0)$ & 0.345 & $38(36.2)$ & $57(44.2)$ & 0.215 & $95(40.6)$ \\
\hline Vocalization exercise & $20(25.0)$ & $49(31.8)$ & 0.278 & $59(27.8)$ & $10(45.5)$ & 0.084 & $22(21.0)$ & $47(36.4)$ & 0.010 & $69(29.5)$ \\
\hline $\begin{array}{l}\text { Using semi-solid and } \\
\text { liquid foods }\end{array}$ & $51(63.7)$ & $116(75.3)$ & 0.063 & $147(69.3)$ & $20(90.9)$ & 0.033 & $73(69.5)$ & $94(72.9)$ & 0.574 & $167(71.4)$ \\
\hline Thickening agent & $68(85.0)$ & $143(92.9)$ & 0.055 & $190(89.6)$ & $21(95.5)$ & $0.705^{\oplus}$ & $95(90.5)$ & $116(89.9)$ & 0.887 & $211(90.2)$ \\
\hline Positioning & $42(52.5)$ & $93(60.4)$ & 0.247 & $122(57.5)$ & $13(59.1)$ & 0.889 & $52(49.5)$ & $83(64.3)$ & 0.022 & $135(57.7)$ \\
\hline $\begin{array}{l}\text { Appropriate approch } \\
\text { for swallowing }\end{array}$ & $39(48.8)$ & $84(54.5)$ & 0.400 & $110(51.9)$ & $13(59.1)$ & 0.520 & $46(43.8)$ & $77(59.7)$ & 0.016 & $123(52.6)$ \\
\hline $\begin{array}{l}\text { Ways to coping when } \\
\text { aspiration }\end{array}$ & $27(33.8)$ & $71(46.1)$ & 0.069 & $87(41.0)$ & $11(50.0)$ & 0.417 & $32(30.5)$ & $66(51.2)$ & 0.001 & $98(41.9)$ \\
\hline \multicolumn{11}{|l|}{ Information } \\
\hline $\begin{array}{l}\text { No. selection; mean }+/- \text { standard } \\
\text { deviation (total } 11 \text { items) }\end{array}$ & $6.06 \pm 2.54$ & $6.89 \pm 2.64$ & $0.022^{\S}$ & $6.49 \pm 2.62$ & $7.77 \pm 2.53$ & $0.029^{\S}$ & $6.18 \pm 2.62$ & $6.95 \pm 2.60$ & $0.025^{\S}$ & $6.61 \pm 2.63$ \\
\hline $\begin{array}{l}\text { No. selection, } \geqq 7 \text { items }{ }^{\dagger} \\
\quad(\text { total } 11 \text { items })\end{array}$ & $31(38.8)$ & $87(56.5)$ & 0.010 & $102(48.1)$ & $16(72.7)$ & 0.028 & $44(41.9)$ & $74(57.4)$ & 0.019 & $118(50.4)$ \\
\hline \multicolumn{11}{|l|}{ [Physical problem] } \\
\hline $\begin{array}{l}\text { Improvement of nutrition } \\
\text { condition }\end{array}$ & $57(71.3)$ & $127(82.5)$ & 0.047 & $167(78.8)$ & $17(77.3)$ & $0.791^{\pi}$ & $76(72.4)$ & $108(83.7)$ & 0.035 & $184(78.6)$ \\
\hline $\begin{array}{l}\text { Low risk of Aspiration-prone } \\
\text { compared to oral intake }\end{array}$ & $59(73.4)$ & $123(79.9)$ & 0.285 & $164(77.4)$ & $18(81.8)$ & $0.791^{\llbracket}$ & $82(78.1)$ & $100(77.5)$ & 0.916 & $182(77.8)$ \\
\hline $\begin{array}{l}\text { Better of nutrition condition } \\
\text { compared to IVH }\end{array}$ & $26(32.5)$ & $90(58.4)$ & $<0.001$ & $100(47.2)$ & $16(72.7)$ & $0.022^{\natural}$ & $42(40.0)$ & $74(57.4)$ & 0.008 & $116(49.6)$ \\
\hline $\begin{array}{l}\text { Advantage and } \\
\text { disadvantage of } \mathrm{TF}\end{array}$ & $41(51.2)$ & $94(61.0)$ & 0.151 & $120(56.6)$ & $15(68.2)$ & 0.295 & $56(53.3)$ & $79(61.2)$ & 0.223 & $135(57.7)$ \\
\hline Complication during insertion & $42(52.5)$ & $87(56.5)$ & 0.560 & $114(53.8)$ & $15(68.2)$ & 0.196 & $59(56.2)$ & $70(54.3)$ & 0.768 & $129(55.1)$ \\
\hline Complication after insertion & $42(52.5)$ & $87(56.5)$ & 0.560 & $114(53.8)$ & $15(68.2)$ & 0.196 & $58(55.2)$ & $71(55.0)$ & 0.976 & $129(55.1)$ \\
\hline
\end{tabular}




\begin{tabular}{|c|c|c|c|c|c|c|c|c|c|c|}
\hline Management after insertion & $59(73.8)$ & $114(74.0)$ & 0.964 & $154(72.6)$ & $19(86.4)$ & 0.163 & $73(69.5)$ & $100(77.5)$ & 0.166 & $173(73.9)$ \\
\hline \multicolumn{11}{|l|}{ [Living problem] } \\
\hline $\begin{array}{l}\text { Technique for the } \\
\text { management of TF }\end{array}$ & $61(76.3)$ & $135(87.7)$ & 0.025 & $175(82.5)$ & $21(95.5)$ & 0.219 & $79(75.2)$ & $117(90.7)$ & 0.001 & $196(83.8)$ \\
\hline Burden of caregiver & $48(60.0)$ & $106(68.8)$ & 0.177 & $137(64.6)$ & $17(77.3)$ & 0.234 & $58(55.2)$ & $96(74.4)$ & 0.002 & $154(65.8)$ \\
\hline $\begin{array}{l}\text { Loss of pleasure to eat } \\
\text { from the mouth }\end{array}$ & $32(40.0)$ & $63(40.9)$ & 0.893 & $85(40.1)$ & $10(45.5)$ & 0.626 & $47(44.8)$ & $48(37.2)$ & 0.242 & $95(40.6)$ \\
\hline Ecomomic burden & $18(22.5)$ & $35(22.7)$ & 0.969 & $45(21.2)$ & $8(36.4)$ & 0.114 & $19(18.1)$ & $34(26.4)$ & 0.133 & $53(22.6)$ \\
\hline
\end{tabular}

Number (\%), p values were tested by Chi-square test, ${ }^{\circ} \mathrm{p}$ values were tested by Fisher's exact test, ${ }^{\S} \mathrm{p}$ values were tested by student's t-test and ${ }^{*} \mathrm{p}$ values was tested by Welch's t-test. Of the 286 nurses, 52 subjects who no experience of tube feeding care were excepted. All questioners were multiple answers. 'Number of interventions was divided into 2 groups, which was used median. ${ }^{* 1}$ Other was included clinic, long-term care facility and home-visit nursing station. TF: Tube Feeding; IVH: Intravenous hyperalimentation.

Table 3. Conference members for decision making of tube feeding or PEG placement.

\begin{tabular}{|c|c|}
\hline & Total \\
\hline & $\mathrm{n}=168$ \\
\hline $\begin{array}{l}\text { Number of conference members; } \\
\text { mean }+/- \text { standard deviation } \\
\text { (total } 12 \text { occupations) }\end{array}$ & $3.42+/-1.44$ \\
\hline \multicolumn{2}{|l|}{ [Conference members] } \\
\hline Primary nurse & $139(82.7)$ \\
\hline Attending physician & $165(98.2)$ \\
\hline Otolaryngologist & $18(10.7)$ \\
\hline Certified nurse of dysphagia nursing & $32(19.0)$ \\
\hline Physical therapist & $18(10.7)$ \\
\hline Occupational therapist & $10(6.0)$ \\
\hline Speech therapist & $100(59.5)$ \\
\hline Dietician & $24(14.3)$ \\
\hline Pharmacist & $2(1.2)$ \\
\hline Discharge planning coordinator ${ }^{\dagger}$ & $52(31.0)$ \\
\hline Medical social worker & $22(13.1)$ \\
\hline Care manager & $23(13.7)$ \\
\hline
\end{tabular}

Number (\%); Of the 234 nurses, $168(71.8 \%)$ carried out a conference at least once. Multiple answers were allowed; ${ }^{\dagger}$ They are a registerd nurse and work for discharge planing and coordination in the hospital.

elderly patients without comorbidities should be on tube feeding, which was a high percentage. In previous studies, approximately $60 \%$ of physicians in the United States and Japan answered that aspiration pneumonia was an indication for PEG placement and was the most common medical indication [13,17]. Knowledge of nurses was consistent with that of physicians. In addition, the percentage of nurses who answered that "dementia" and "malnutrition in frail, elderly patients without comorbidities" were also significantly higher in those with more tube feeding experience than in those with none or less tube feeding experience. This result might be affected by the current guidelines for the use of PEG because PEG placement is indicated in the elderly with recurrent aspiration pneumonia or those that do not eat voluntarily because of cerebrovascular disease or dementia in "guidelines for PEG in Japan" [18]. Thus, the indication for PEG in the elderly should be widely discussed in the future, and hence, the guidelines should be revised for the indications of tube feeding including PEG.

Concerning nursing care practices before introducing tube feeding, the mean number of interventions for swallowing disorders and the information given was six items, which was not that many. Nurses with more tube feeding experience performed significantly more interventions and provided more information than those with less tube feeding experiences. Among the [15] intervention items used before introducing tube feeding, over $70 \%$ of the nurses answered that "thickening agent" and "using semisolid and liquid foods" were given to patients with swallowing disorders. "Consultation with a speech therapist" was also usually performed. In contrast, rehabilitation for the improvement of swallowing dysfunction was not frequently performed, and neither was a screening test. In Japan in 2006, the certified nurse of dysphagia designation nursing was established and as of April 2012 there were only 302 certified nurses of dysphagia in Japan [19]. The hospital in this study had only one certified nurse of dysphagia nursing for approximately 1200 beds. In the future, improving the quality of further training for professionals and generalists will be needed. Our results indicated that nurses did not usually give information about "economic burden" before beginning tube feeding. In Japan, nutritional supplementation for different digestion states and elemental supplementation are classified as "medicine", whereas high-density liquid diets are classified as "food", which is not covered by health insurance. For this reason, elderly patients on tube feeding at home have a high economic burden because high-density liquid diet is more expensive than general foods. Therefore, the 
Table 4. Multivariate-adjusted odds ratios and $95 \%$ confidence intervals for frequency and the conference members according to the knowledge and practice of tube feeding.

\begin{tabular}{|c|c|c|c|c|c|}
\hline & \multicolumn{5}{|c|}{ Conference } \\
\hline & \multirow[t]{2}{*}{ Non } & \multicolumn{2}{|c|}{ Occasional } & \multicolumn{2}{|c|}{ Every time } \\
\hline & & \multicolumn{2}{|c|}{ Participating occupation } & \multicolumn{2}{|c|}{ Participating occupation } \\
\hline & $\mathrm{n}=66$ & $\begin{array}{c}\text { Few } \\
\mathrm{n}=69\end{array}$ & $\begin{array}{l}\text { Multidisciplinary } \\
\quad \mathrm{n}=54\end{array}$ & $\begin{array}{c}\text { Few } \\
\mathrm{n}=25\end{array}$ & $\begin{array}{l}\text { Multidisciplinary } \\
\quad \mathrm{n}=20\end{array}$ \\
\hline & & OR $(95 \% \mathrm{CI})$ & OR $(95 \% \mathrm{CI})$ & OR $(95 \% \mathrm{CI})$ & OR $(95 \% \mathrm{CI})$ \\
\hline \multicolumn{6}{|l|}{$\begin{array}{l}\text { Is the following disorder an } \\
\text { indication for TF? }\end{array}$} \\
\hline Head injury or facial trauma & ref & $1.00(0.26-3.79)$ & $1.37(0.30-6.26)$ & $0.69(0.15-3.30)$ & $0.45(0.09-2.23)$ \\
\hline Oropharyngeal malignancy & ref & $0.49(0.13-1.86)$ & N.D (N.D) & $0.41(0.08-2.06)$ & $0.96(0.10-9.60)$ \\
\hline Neurological disorder & ref & $1.23(0.25-6.02)$ & $1.51(0.25-9.02)$ & $0.76(0.12-4.65)$ & $0.50(0.08-3.19)$ \\
\hline Stroke & ref & $0.88(0.29-2.62)$ & $1.80(0.48-6.77)$ & $0.40(0.11-1.41)$ & $0.70(0.15-3.14)$ \\
\hline Dementia & ref & $1.62(0.74-3.56)$ & $1.73(0.76-3.95)$ & $0.29(0.06-1.39)$ & $2.16(0.73-6.42)$ \\
\hline $\begin{array}{l}\text { Aspiration-prone frail elderly } \\
\text { without comorbidity }\end{array}$ & ref & $0.40(0.19-0.84)$ & $1.04(0.46-2.36)$ & $0.37(0.13-1.00)$ & $0.37(0.12-1.11)$ \\
\hline $\begin{array}{l}\text { Malnutrition in frail elderly } \\
\text { without comorbidity }\end{array}$ & ref & $0.95(0.41-2.21)$ & $1.79(0.77-4.18)$ & $1.36(0.45-4.10)$ & $0.76(0.21-2.73)$ \\
\hline $\begin{array}{l}\text { How long does a patient need to survive } \\
\text { after PEG placement? } \geqq 12 \text { weeks }^{{ }^{* 1}}\end{array}$ & ref & $1.18(0.55-2.53)$ & $2.23(1.01-4.90)$ & $0.92(0.33-2.57)$ & $0.54(0.15-1.88)$ \\
\hline \multicolumn{6}{|l|}{$\begin{array}{l}\text { Intervention for swallowing } \\
\text { disorder before using TF }\end{array}$} \\
\hline No. intervention, $\geqq 6$ items $^{* 2}$ & ref & $2.13(1.07-4.24)$ & $4.69(2.14-10.28)$ & $1.78(0.70-4.50)$ & $6.56(1.97-21.85)$ \\
\hline \multicolumn{6}{|l|}{ Information for using $\mathrm{TF}$} \\
\hline No. selection, $\geqq 7$ items $^{* 3}$ & ref & $1.78(0.84-3.76)$ & $4.66(2.06-10.55)$ & $6.40(2.23-18.41)$ & $4.74(1.54-14.53)$ \\
\hline
\end{tabular}

Dependent variables: knowledge and practice of TF. Independent variables: frequency and the conference members (ref: non conference, 1: occasional and less than 4 different health care professionals, 2 : occasional and $\geqq 4$ different health care professionals, 3 : every time and less than 4 different health care professionals, 4: every time and $\geqq 4$ different health care professionals); Adjusted for clinical experience, history of working place and Experience of tube feeding care; ${ }^{* 1}$ The period expected to survive after PEG was divided into two groups ( $1: \geqq 12$ weeks, $0:<12$ weeks). ${ }^{*}$ Number of intervention items were divided into two groups, which was used median value into 15 items ( $1: \geqq 6$ items, $0:<6$ items). ${ }^{* 3}$ Number of selection items were divided into two groups, which was used median value into 11 items (1: $\geqq 7$ items, $0:<7$ items). OR: Odds Ratio; 95\% CI: 95\% confidence interval; TF: Tube Feeding; N.D: Not Dedetermined.

cost of enteral nutrient should be widely known by nurses.

It is interesting to note the relationship between multidisciplinary teams and the practice of tube feeding. In the present study, we showed that those who have a multidisciplinary team for patients receiving tube feeding tended to perform more "interventions for dysphagia and information before using tube feeding" compared with the reference group, as shown by multivariate analysis. We assume that a team with different health care professionals makes nurses more careful before PEG placement. A previous study developed by Japanese geriatricians and other studies reported consistent results showing that evaluation and management by multidisciplinary teams during hospitalization had a documented lower rate of institutionalization after 1 year $[13,20]$.

Consequently, a multidisciplinary approach such as comprehensive geriatric assessment is effective for the care for frail older persons admitted to the hospital because older patients have many risks factors for developing typical geriatric syndromes. Furthermore, decision making on the treatment strategy should be discussed in a multidisciplinary team including several team members with different educational backgrounds and experiences. The multidisciplinary team would provide a better answer for each elderly patient with a complicated history who needs tube feeding.

However, our results did not show a relationship between multidisciplinary teams and understanding of the indications for tube feeding. Our previous study of Japanese geriatricians did not show a relationship either [13], implying that team might not affect the decisions for tube feeding by geriatricians. The decision to start or withhold tube feeding by physicians was associated with liability concerns of the physician [21]. Thus, the multi- 
disciplinary team might become a good opportunity for appropriate decision making on whether to start or withhold tube feeding. From these results we think that nurses should make more chances to discuss with other medical staffs about tube feeding for older adult patients.

Several potential limitations should be considered when interpreting these results. First, in this study, the questions did not specify the stage of disorders or the level of conditions, including advanced dementia; therefore, our results should be interpreted with caution. The European Guidelines do recommend tube feeding for persons with early or moderate dementia, but not severe dementia [15, 16]. Second, we asked about tube feeding including NGT, PEG and enterostomy. Therefore, the main results might be different between invasive PEG and less-invasive NGT. However, we should discuss several options and not only PEG with patients and/or their families when the patient cannot eat food. Accordingly, "tube feeding" was defined as all types of tube feeding nutrition including NGT, PEG and enterostomy tube in this study. Third, a cross-sectional study does not prove any causal relationship. Fourth, the practice rate by nurses before using tube feeding was not clearly determined because this study was performed by self-administered questionnaires. Finally, the subjects were limited to nurses who worked in a university hospital. Therefore, social desirability bias may have driven some results, such as whether nurses reported taking part in the multidisciplinary team. However, we collected questionnaires separately to promote honest responses. In addition, selection bias may have occurred. However, these results might be characteristic of general nurses working in an acute general hospital.

In conclusion, our data indicated that approximately $40 \%$ of registered nurses consider the purpose of tube feeding to be improving the QOL in the elderly with eating problems. Furthermore, approximately $30 \%$ of the Japanese nurses thought that demented elderly patients with loss of appetite or eating apraxia should be on tube feeding. In contrast, more than half of the nurses answered that aspiration-prone, frail, elderly patients without comorbidities is an indication. The percentage of nurses who answered that aspiration-prone, frail, elderly patients without comorbidities was an indication for tube feeding was higher in those nurses with more tube feeding experience. Currently, there is no consensus among Japanese geriatricians about tube feeding for patients with advanced dementia, and hence, guidelines should be established for tube feeding in the elderly. Furthermore, the multidisciplinary team approach is expected to produce better treatment and care, including for the indication of tube feeding for elderly patients with eating difficulties. The multidisciplinary team may improve the decision-making process for nurses.

\section{Acknowledgements}

We would like to thank all the nurses who participated in our study for their kind help. We would also like to thank Priscila Yukari Sewo Sampaio for her critical reading of our manuscript.

\section{REFERENCES}

[1] J. C. Ahronheim, M. Mulvihill, C. Sieger, et al. "State Practice Variations in the Use of Tube Feeding for Nursing Home Residents with Severe Cognitive Impairment," Journal of the American Geriatrics Society, Vol. 49, No. 2, 2001, pp. 148-152. doi:10.1046/j.1532-5415.2001.49035.x

[2] S. L. Mitchell, J. M. Teno, J. Roy, et al., "Clinical and Organizational Factors Associated with Feeding Tube Use among Nursing Home Residents with Advanced Cognitive impairment," Journal of the American Medical Association, Vol. 290, No. 1, 2003, pp. 73-80. doi:10.1001/jama.290.1.73

[3] Y. Hirakawa, Y. Masuda, T. Kimata, et al., "Terminal Care for Elderly Patients with Dementia in Two Long-Term Care Hospitals," Nihon Ronen Igakkai Zasshi, Vol. 41, No. 1, 2004, pp. 99-104 (in Japanese). doi:10.3143/geriatrics.41.99

[4] G. Bellelli, G. B. Frisoni and M. Trabucchi, "Feeding Tube Use in Italian Nursing Homes: The Role of Cultural Factors," Journal of the American Medical Directors Association, Vol. 6, No. 1, 2005, pp. 87-88. doi:10.1016/j.jamda.2004.12.014

[5] T. E. Finucane, C. Christmas and K. Travis, "Tube Feeding in Patients with Advanced Dementia: A Review of the Evidence," Journal of the American Medical Association, Vol. 282, No. 14, 1999, pp. 1365-1370. doi:10.1001/jama.282.14.1365

[6] M. R. Gillick, "Rethinking the Role of Tube Feeding in Patients with Advanced Dementia," The New England Journal of Medicine, Vol. 342, No. 3, 2000, pp. 206-210. doi:10.1056/NEJM200001203420312

[7] M. A. Rudberg, B. L. Egleston, M. D. Grant, et al., "Effectiveness of Feeding Tubes in Nursing Home Residents with Swallowing Disorders," Journal of Parenteral and Enteral Nutrition, Vol. 24, No. 2, 2000, pp. 97-102. doi: $10.1177 / 014860710002400297$

[8] D. E. Meier, J. C. Ahronheim, J. Morris, et al., "High Short-Term Mortality in Hospitalized Patients with Advanced Dementia: Lack of Benefit of Tube Feeding," Archives of Internal Medicine, Vol. 161, No. 4, 2001, pp. 594-599. doi:10.1001/archinte.161.4.594

[9] Y. Tokuda and H. Koketsu, "High Mortality in Hospitalized Elderly Patients with Feeding Tube Placement," Internal Medicine, Vol. 41, No. 8, 2002, pp. 613-616. doi:10.2169/internalmedicine.41.613

[10] L. M. Murphy and T. O. Lipman, "Percutaneous Endoscopic Gastrostomy Does Not Prolong Survival in Patients with Dementia," Archives of Internal Medicine, Vol. 163, No. 11, 2003, pp. 1351-1353. doi:10.1001/archinte.163.11.1351 
[11] D. I. Gaines, V. Durkalski, A. Patel, et al., "Dementia and Cognitive Impairment Are Not Associated with Earlier Mortality after Percutaneous Endoscopic Gastrostomy," Journal of Parenteral and Enteral Nutrition, Vol. 33, No. 1, 2009, pp. 62-66. doi:10.1177/0148607108321709

[12] Y. Suzuki, S. Tamez, A. Murakami, et al., "Survival of Geriatric Patients after Percutaneous Endoscopic Gastrostomy in Japan," World Journal of Gastroenterology, Vol. 16, No. 40, 2010, pp. 5084-5091. doi:10.3748/wjg.v16.i40.5084

[13] M. Ogita, H. Utsunomiya, M. Akishita, et al., "Indications and Practice for Tube Feeding in Japanese Geriatricians: Implications of Multidisciplinary Team Approach," Geriatrics \& Gerontology International, Vol. 12, No. 4, 2012, pp. 643-651. doi:10.1111/j.1447-0594.2011.00831.x

[14] J. Richter and M. R. Eisemann, "Attitudinal patterns Determining Decision-Making in the Treatment of the Elderly: A Comparison between Physicians and Nurses in Germany and Sweden," Intensive Care Medicine, Vol. 26, No. 9, 2000, pp. 1326-1333. doi:10.1007/s001340000602

[15] D. Volkert, Y. N. Berner, E. Berry, et al., "ESPEN Guidelines on Enteral Nutrition: Geriatrics," Clinical Nutrition, Vol. 25, No. 2, 2006, pp. 330-360. doi:10.1016/j.clnu.2006.01.012

[16] L. Sobotka, S. M. Schneider, Y. N. Berner, et al., "ESPEN
Guidelines on Parenteral Nutrition: Geriatrics," Clinical Nutrition, Vol. 28, No. 4, 2009, pp. 461-466. doi:10.1016/j.clnu.2009.04.004

[17] C. A. Vitale, T. Hiner, W. A. Ury, et al., "Tube Feeding in Advanced Dementia: An Exploratory Survey of Physician Knowledge," Care Management Journals, Vol. 7, No. 2, 2006, pp. 79-85. doi:10.1891/cmaj.7.2.79

[18] The Japan Gastroenterological Endoscopy Society, "Practical Guidelines for Gastroenterological Endoscopy," In: Guideline of Percutaneous Endoscopic Gastrostomy, 3rd Edition, Igaku-shoin Co., Ltd., Tokyo, 2006.

[19] Japanese Nursing Association, "Number of Certified Nurse for Dysphagia in April 2012 in Japan," 2012. http://www.nurse.or.jp/nursing/qualification/nintei/pdf/cn suii.pdf

[20] K. Van Craen, T. Braes, N. Wellens, et al., "The Effectiveness of Inpatient Geriatric Evaluation and Management Units: A Systematic Review and Meta-Analysis," Journal of the American Geriatrics Society, Vol. 58, No. 1, 2010, pp. 83-92. doi:10.1111/j.1532-5415.2009.02621.x

[21] C. Bell, E. Somogyi-Zalud, K. Masaki, et al., "Factors Associated with Physician Decision-Making in Starting Tube Feeding," Journal of Palliative Medicine, Vol. 11, No. 6, 2008, pp. 915-924. doi:10.1089/jpm.2007.0289 